\title{
Nanofiltration and Fenton's process over iron shavings for surfactants removal
}

\section{Rui C. Martins, Marta Nunes, Licínio M. Gando-Ferreira \& Rosa M. Quinta- Ferreira}

To cite this article: Rui C. Martins, Marta Nunes, Licínio M. Gando-Ferreira \& Rosa M. QuintaFerreira (2014) Nanofiltration and Fenton's process over iron shavings for surfactants removal, Environmental Technology, 35:18, 2380-2388, DOI: 10.1080/09593330.2014.906507

To link to this article: https://doi.org/10.1080/09593330.2014.906507

曲 Published online: 29 Apr 2014.

Submit your article to this journal $₫$

III Article views: 92

View Crossmark data \ulcorner

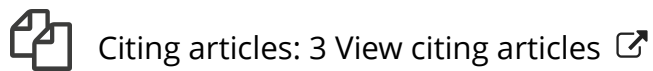




\title{
Nanofiltration and Fenton's process over iron shavings for surfactants removal
}

\author{
Rui C. Martins, Marta Nunes, Licínio M. Gando-Ferreira* and Rosa M. Quinta-Ferreira \\ Chemical Processes and Forest Products Research Centre (CIEPQPF), GERST, Group on Environment, Reaction, and Separation and \\ Thermodynamics, Department of Chemical Engineering, Faculty of Sciences and Technology, University of Coimbra, Pólo II-Rua \\ Sílvio Lima, 3030-790 Coimbra, Portugal
}

(Received 10 October 2013; accepted 14 March 2014)

\begin{abstract}
The presence of surfactants in wastewater composition tends to jeopardize the efficiency of the traditional aerobic treatment processes. In this regard, the application of Fenton's reaction and nanofiltration as single processes and integrated (nanofiltration followed by Fenton's process) was investigated on the abatement of a solution containing two surfactants usually found in effluents coming from detergent industry (dodecylbenzene - DDB and sodium lauryl ether sulphate - SLES). The potential of a solid waste (iron shavings) as catalyst in the Fenton's process was evaluated and the reaction system was optimized regarding the key operating parameters (iron and hydrogen peroxide concentration and $\mathrm{pH}$ ). The highest chemical oxygen demand (COD) degradation $(66 \%)$ was attained for $\mathrm{pH} 3,\left[\mathrm{H}_{2} \mathrm{O}_{2}\right]=32 \mathrm{mM}$ and $50 \mathrm{~g} / \mathrm{L}$ of iron shavings. Besides, it was concluded that oxidation was due to hydroxyl radicals adsorbed on the metal surface even if bulk interaction between hydrogen peroxide and dissolved iron cannot be neglected. The main variables ruling nanofiltration were evaluated ( $\mathrm{pH}$, temperature and cross-flow rate). Eighty-four percent of COD rejection was determined at $\mathrm{pH} 7.5$, cross-flow $14.4 \mathrm{~cm}^{3} \mathrm{~s}^{-1}, 20^{\circ} \mathrm{C}$ and 15 bar of pressure drop. Finally, nanofiltration followed by Fenton's process under the best conditions was integrated; however, no significant improvement was attained with $85 \%$ of COD being globally removed.
\end{abstract}

Keywords: Fenton's process; nanofiltration; processes integration; surfactants; detergent industry wastewater

\section{Introduction}

Nowadays, mankind starts to concern with environment protection related with the excessive resources consumption and pollution. The industrial activity has an important responsibility spending a large amount of assets to satisfy the needs and producing a large quantity of solid, liquid and gaseous residues that must be treated before final release to the surroundings.

The presence of surfactants in the effluents jeopardize the efficiency of the traditional biological aerobic systems once these compounds confer biorefractory character and difficult the reactors aeration. Besides, these substances tend to bio-accumulate threatening the ecosystems.[1] The impact of these compounds is important not only on the analysis of the treatment of detergent industry wastewaters but also on the depuration of municipal effluents once the release of these substances into the domestic sewage interferes in the efficiency of the municipal wastewater treatment plants.[2] This highlights the importance of investigating and optimizing technologies capable of removing surfactants from the water streams. The application of advanced oxidation processes (AOPs) and/or membrane separation technologies (MSPs) can overcome these fragilities of the classic depuration systems. Among the AOPs, Fenton's process is arising as industrially interesting due to the easiness on reactants handling and low-cost operation. [3] This technology is based upon the hydrogen peroxide oxidant power enhanced by ferrous salts.[4,5] However, the high amount of iron sludges produced at the end of the treatment constitutes the main drawback of this technique when operated under homogeneous liquid systems. Therefore, some studies have been conducted trying to select a suitable solid catalyst able to be applied in Fenton's peroxidation.[6-8] Recently, some investigation efforts were performed to analyse the ability of iron wastes (such as iron shavings) to be used as low-cost catalyst in this treatment.[9] MSPs, such as nanofiltration, use semipermeable membranes to separate the feeding mixture into two streams, permeate and retentate.[10] Nanofiltration is characterized by operating pressures within the range 5-40 bar and membrane pore sizes between 0.5 and $2 \mathrm{~nm}$. These membrane technologies present the advantages of not requiring chemical addition besides the moderately low-energy consumption and the mild conditions needed for separation.

There are some studies in literature regarding the depuration of detergents containing effluents. Mensah and Foster [11] analysed the performance of an anaerobic digestor on the treatment of a simulated surfactant mixture; however, it was verified that high concentrations provoked the disruption of the biological filter. A solution of sodium dodecyl

\footnotetext{
*Corresponding author. Email: 1ferreira@eq.uc.pt
} 
sulphate was treated by ultrafiltration using a polysulfone membrane with a cut-off of $5 \mathrm{kDa}$ with a global chemical oxygen demand (COD) removal within 65-85\%.[12] Fenton's process was analysed by various authors on the depuration of surfactant effluents.[13-16] Bautista et al. [2] and Naumczyk et al. [17] conducted studies with the classic Fenton's process for the treatment of a real cosmetic wastewater. Trying to overcome the drawback associated with the iron sludge production in the homogeneous process, Martins et al. [16] tested the applicability of a solid catalyst $(\mathrm{Fe}-\mathrm{Ce}-\mathrm{O})$ to enhance hydrogen peroxide action for the degradation of an actual detergent industry effluent and enhance its biodegradability. Integrated systems such as Fenton's process followed by aerobic digestion [18] were also evaluated to maximize the depuration and biodegradability enhancement of this kind of wastewater. Nanofiltration was applied with good results for surfactants removal from water.[19,20]

Within this scope, the aim of the present research was to analyse the possibility of using a low-cost catalyst (iron shavings, which are wastes from iron processing industry) for the degradation of a simulated mixture of surfactants. Besides, nanofiltration was also optimized for the same effluent. The final goal was to integrate both processes (nanofiltration followed by Fenton's process) to promote water reuse.

\section{Experimental}

\subsection{Oxidation procedure}

Fenton's process was carried out in batch reactors stirred in an orbital shaker. First, the effluents' pH (measured with a Crison micro $\mathrm{pH}$ ) was set at the desired value using either sulphuric acid $(0.1 \mathrm{M})$ or sodium hydroxide $(0.1 \mathrm{M})$ and a certain load of iron shavings was added. The reaction started when hydrogen peroxide (industrial, 50\%) was introduced. At the end of each experiment, the samples withdrawn were filtrated to remove the catalyst and alkalinized to eliminate the remaining $\mathrm{H}_{2} \mathrm{O}_{2}$, which interferes with the analytical techniques.

\subsection{Nanofiltration procedure}

Nanofiltration was performed in batch mode in a flat-sheet laboratory scale, cross-flow membrane filtration apparatus encompassing a membrane module, a diaphragm pump, a reservoir, valves and sensors as described elsewhere.[21] A Desal 5 DK (GE OSMONICS) membrane consisting of a thin-film of polyamide composite $\left(140 \mathrm{~cm}^{2}\right.$ of filtration area) was tested. The molecular weight cut-off of the Desa15 DK lies between 200 and 300. First, the membrane was wetted with distillate water during $30 \mathrm{~min}$ at 10 bar. Preliminary experiments were carried out to assess the time required for the system to reach steady state (which was concluded to be $15 \mathrm{~min}$ ) and the hydrodynamic membrane resistance
$\left(R_{\mathrm{m}}\right)$. This process performance on removing surfactants was evaluated by changing the key operating parameters, $\mathrm{pH}$, drop pressure, cross-flow rate and temperature.

\subsection{Wastewater preparation, catalyst and analytical techniques}

The effluent was prepared using two of the most significant surfactants present in the real wastewater from a detergent industry nearby, namely dodecylbenzene (DDB) and sodium lauryl ether sulphate (SLES). The average molecular weight of these surfactants is higher than $300 \mathrm{~g} / \mathrm{mol}$. According to the stakeholder, the maximum total concentration on surfactants of the actual stream is around $2 \mathrm{~g} / \mathrm{L}$, thus the simulated mixture was prepared, using equal concentrations of each substance until fulfilling this threshold.

The catalyst consisted in iron shavings (zero-valent iron, ZVI) are wastes from iron processing industry. Once ZVI was very difficult to mill, the particles were used at their original size $(0.814-1.140 \mathrm{~mm})$. The ZVI composition in $\mathrm{N}, \mathrm{C}, \mathrm{H}$ and $\mathrm{S}$ was determined by elemental analysis using a Fisons Instruments EA 1108 CHNS-O while its content in metals was assessed after acid digestion by atomic absorption spectophotometry (Perkin-Elmer 3300). The specific surface area $\left(S_{\mathrm{BET}}\right)$ was obtained with an accelerated surface area equipment (ASAP 2000, Micromeritics). Finally, the crystalline structure was inferred by X-ray diffraction (Philips PW 3040/00 X'Pert Analyser).

The COD was determined according to the closed reflux colorimetric Standard Method 5220D,[22] where the samples were digested during $2 \mathrm{~h}$ at $150^{\circ} \mathrm{C}$ in a WTW CR3000 instrument and the COD was directly read in a WTW MPM3000 photometer at $605 \mathrm{~nm}$. Biochemical oxygen demand $\left(\mathrm{BOD}_{5}\right)$ was obtained by measuring the dissolved oxygen concentration (WTW INOLab 740) before and after 5 days of incubation of microorganisms coming from garden soil.[22]

The critical micelle concentration (CMC) of the surfactants was determined according to the procedure described by Kertész et al.[20] Briefly, solutions with different concentrations were prepared and their conductivities at different temperatures $\left(20,30\right.$ and $\left.40^{\circ} \mathrm{C}\right)$ were determined (MultiParameter Analyser CONSORT C86); this parameter is directly proportional to concentration and the point where the formation of the micelles starts is indicated by a breaking point on this dependence.

\section{Results and discussion}

\subsection{Effluents and catalyst characterization}

The synthetic effluent comprising two surfactants that are commonly present in detergent industry wastewaters was prepared to present a COD value around the one determined for the actual wastewater $\left(2255 \pm 180 \mathrm{mg} \mathrm{O}_{2} / \mathrm{L}\right)$ and 

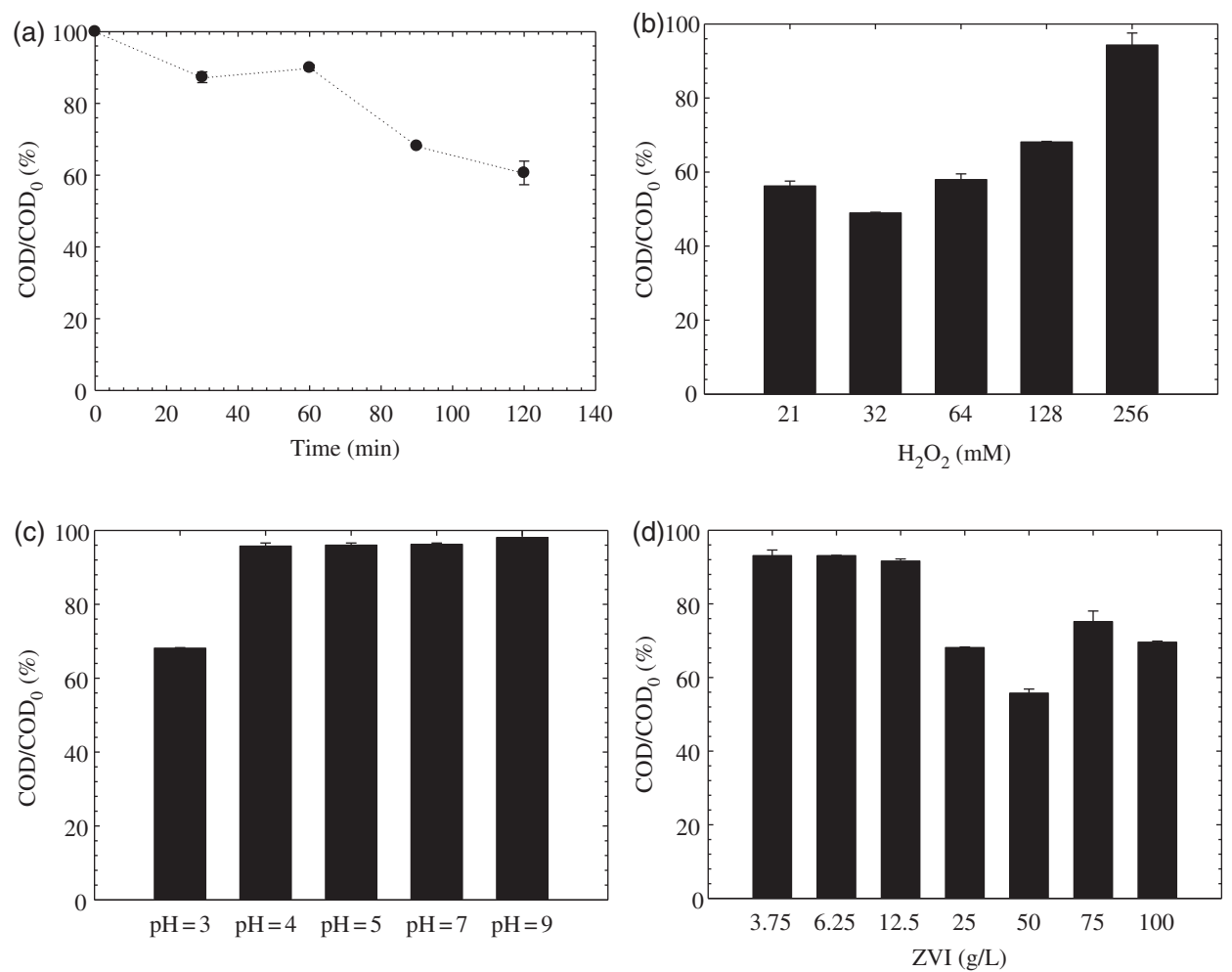

Figure 1. (a) COD abatement trend along time during Fenton's peroxidation over iron shavings ( $\mathrm{pH} 3$, $\left[\mathrm{H}_{2} \mathrm{O}_{2}\right]=128 \mathrm{mM}$ and $25 \mathrm{~g} / \mathrm{L}$ of catalyst). (b) Effect of hydrogen peroxide concentration on the efficiency of Fenton's process regarding COD removal (25 g/L of iron shavings, $\mathrm{pH} 3$ and 90 min of reaction). (c) Effect of $\mathrm{pH}$ on the efficiency of Fenton's process regarding COD removal $\left(\left[\mathrm{H}_{2} \mathrm{O}_{2}\right]=128 \mathrm{mM}, 25 \mathrm{~g} / \mathrm{L}\right.$ and 90 min of reaction). (d) Effect of iron shavings load on the efficiency of Fenton's process regarding COD removal $\left(\left[\mathrm{H}_{2} \mathrm{O}_{2}\right]=128 \mathrm{mM}\right.$, $\mathrm{pH} 3$ and 90 min of reaction).

a global surfactant concentration of $2 \mathrm{~g} / \mathrm{L}$ (the maximum value reported by the industrial plant). Moreover, an initial $\mathrm{BOD}_{5}$ of $1400 \pm 280 \mathrm{mg} \mathrm{O}_{2} / \mathrm{L}$ was also determined; this leads to a $\mathrm{BOD}_{5} / \mathrm{COD}$ ratio of 0.6 , which is above the threshold commonly accepted to consider a stream to be completely biodegradable ( 0.4 according to Esplugas et al. [23]). However, the application of activated sludge treatments is usually unsuccessful for this kind of effluent. This is due to the presence of large amounts of surfactants that difficult the reactors aeration. On the other hand, the strong variability of the wastewater composition (function of the kind of product being processed) would entail continuous microorganism adaptation. In addition, this solution presented a $\mathrm{pH}$ of 3.0.

According to Archer et al.,[24] in nanofiltration of surfactants, the rejection values tend to increase in the $\mathrm{CMC}$ region. In our experiments, the mixture concentration always presents values below the CMC.

\subsection{Fenton's process}

In this section, the results regarding the application of Fenton's process over iron shavings for the degradation of the simulated mixture encompassing the surfactants DDB and SLES are presented and discussed. The amount of hydrogen peroxide theoretically required for the complete oxidation of the effluent $(128 \mathrm{mM})$ was determined according to the initial COD.[25]

\subsubsection{Effect of operation time}

The treatment operation time is an important factor since it will influence the volume of the reactors required for the process. In this context, the COD abatement of the simulated effluent was followed up through time when Fenton's process was applied using $128 \mathrm{mM}$ of hydrogen peroxide, $\mathrm{pH} 3$ and $25 \mathrm{~g} / \mathrm{L}$ of iron shavings. This load of catalyst was selected due to the previous results attained on the depuration of landfill leachate by this system.[9] Figure 1(a) depicts the temporal trend of COD during the depuration process.

The results show a decrease in COD along time with about $32 \%$ depleted after $60 \mathrm{~min}$ and $40 \%$ after $120 \mathrm{~min}$, which corresponded to a final value of $1335 \mathrm{mg} \mathrm{O}_{2} / \mathrm{L}$. It should be noticed that the deviations between trials was always around $3 \%$. The following experiments were performed for a fixed reaction time of $90 \mathrm{~min}$.

\subsubsection{Effect of hydrogen peroxide concentration}

Hydrogen peroxide concentration is a key operating parameter that may determine both the process efficiency and cost. 
With this ambit, the effect of $\left[\mathrm{H}_{2} \mathrm{O}_{2}\right]$ was evaluated within a range 21 (1/6 of the stoichiometric value) $-256 \mathrm{mM}$ (the double of the theoretical amount required for total oxidation) using $90 \mathrm{~min}$ of reaction, $25 \mathrm{~g} / \mathrm{L}$ of ZVI and $\mathrm{pH} 3$. The results regarding COD abatement at the end of oxidation are shown in Figure 1(b) revealing that an increase in the oxidant load from 21 to $32 \mathrm{mM}$ enhanced the depuration with COD abatement increasing from $46 \%$ to $52 \%$. However, for higher concentrations the opposite effect is evident. In fact, for $256 \mathrm{mM} \mathrm{COD}$, removal is below $10 \%$. This is explained by the radical scavenger effect of hydrogen peroxide, which when in excess promotes the production of hydroperoxide radicals with much lower oxidant power than hydroxyl, inhibiting, this way, the treatment efficacy.[26]

\subsubsection{Effect of $p H$}

The effect of $\mathrm{pH}$ over the process efficiency was also assessed within the range 3-9. The iron shavings and hydrogen peroxide concentration were fixed in $25 \mathrm{~g} / \mathrm{L}$ and $128 \mathrm{mM}$, respectively. Figure 1(c) shows the COD abatement after $90 \mathrm{~min}$ of reaction. It is clear that $\mathrm{pH} 3$ is the most favourable one for this process as already reported in literature.[27] At these conditions, COD removal reaches $32 \%$, whereas for higher $\mathrm{pH}$ values a strong inhibition occurred with depuration barely grasping $5 \%$. This behaviour may be attributed to the enhanced decomposition of hydrogen peroxide in water and oxygen for high $\mathrm{pH}$ values, which reduces the amount of oxidant available for the production of hydroxyl radicals.[28] On the other hand, it was observed that with the $\mathrm{pH}$ decrease the iron sludge produced at the end of the experiment increased. This is probably related with the augment in Fe leached [29] for acidic conditions. Somehow, this fact may also be an explanation for the lower efficiency of this catalytic system when more alkaline solutions were used if the hydroxyl radicals are mainly produced in solution due to the interaction between hydrogen peroxide and dissolved ferrous ions and not by the direct reaction of the oxidant over the $\mathrm{Fe}^{0}$ surface. This will be further discussed in a following section.

\subsubsection{Effect of ZVI concentration}

The effect of the load of iron shavings over the oxidation process efficiency was evaluated using amounts within the range $3.75-100 \mathrm{~g} / \mathrm{L}$. The selected operation time was $90 \mathrm{~min}$, the $\mathrm{pH}$ was fixed in 3 and the concentration of hydrogen peroxide in $128 \mathrm{mM}$. The COD removal percentages at the end of the reaction are represented in Figure 1(d) as a function of ZVI load.

As it can be observed, for low catalyst concentrations (below $12.5 \mathrm{~g} / \mathrm{L}$ ) COD degradation does not reach $10 \%$ in $90 \mathrm{~min}$. Nevertheless, a high improvement is observed afterwards with the maximum depuration being reached for $50 \mathrm{~g} / \mathrm{L}$ of iron shavings with $45 \%$. The further increase in the ZVI amount introduced in the reactor decreased the efficiency, which may be related to the scavenger effect due to an excess of iron leading to a reduction in the quantity of hydroxyl radicals available for reaction.

\subsubsection{Optimal conditions}

To refine the optimal conditions, several iron shavings' loads were tested $(25-100 \mathrm{~g} / \mathrm{L})$ together with different hydrogen peroxide concentrations $(32-128 \mathrm{mM})$ at a fixed $\mathrm{pH}$ of 3 since it is well known that there is a strong interaction between these two variables. The COD abatement results attained after $90 \mathrm{~min}$ of Fenton-like reaction are reported in Figure 2(a).

As it can be observed, whichever may be the catalyst load introduced in the reactor, the highest COD depuration is attained when $\left[\mathrm{H}_{2} \mathrm{O}_{2}\right]=32 \mathrm{mM}$ with degradation ranging within the values $52-66 \%$. Therefore, to establish the best iron shavings amount one can observe the behaviour of COD depleted in this case. It is obvious that there was an improvement when that quantity was changed from 25 to $50 \mathrm{~g} / \mathrm{L}$, as COD abatement increases from $52 \%$ to $61 \%$. Nevertheless, for higher concentrations (50-100 g/L) organic matter abatement oscillates between $61 \%$ and $66 \%$ representing a difference of $5 \%$, which is within the experimental error associated with the technique as referred before. Therefore, the criterion for selecting the best iron shavings load has into account the operating costs for a future industrial plant; thus, the $50 \mathrm{~g} / \mathrm{L}$ was chosen.

An important aspect of using AOPs is related with their ability to enhance the effluents biodegradability so that a subsequent and inexpensive biological process may be applied afterwards to refine the wastewater, generally in municipal treatment plants. In this context, the ratio $\mathrm{BOD}_{5} / \mathrm{COD}$ was evaluated for the raw stream after being subjected to the Fenton's process over $50 \mathrm{~g} / \mathrm{L}$ of iron shavings, $\mathrm{pH} 3$ during $90 \mathrm{~min}$ at different hydrogen peroxide concentrations. As it can be observed in Figure 2(b), biodegradability increases relatively the raw effluent's characteristics when $\left[\mathrm{H}_{2} \mathrm{O}_{2}\right]=21,64$ and $256 \mathrm{mM}$ leading to $\mathrm{BOD}_{5} / \mathrm{COD}$ values of about 0.8 when compared with 0.6 initially determined. Contrarily, for the optimum hydrogen peroxide concentration, $32 \mathrm{mM}$, which reached the maximum COD removal, a biodegradability decrease was observed to around 0.30 . It seems thus that the organic matter removed at these conditions results in an effluent with more bio-refractory characteristics than the original mixture, which is not the case for the other hydrogen peroxide loads that were tested.

\subsubsection{Effect of the presence of radical scavengers}

The role of ZVI (which is the case of our iron shavings) on Fenton's like treatment efficiency is not clear. If some authors refer that this process is mainly heterogeneous, with hydroxyl radicals being produced due to the decomposition 

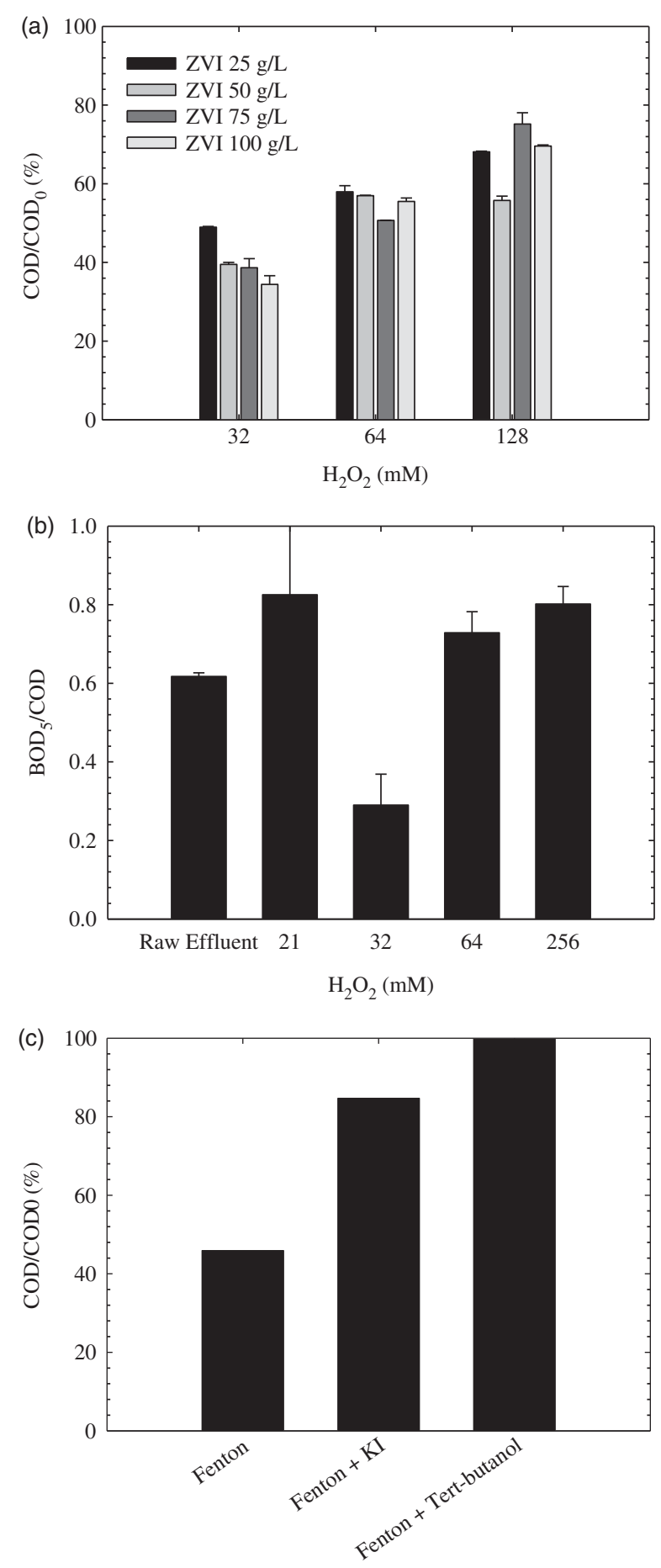

Figure 2. (a) Final COD removal for several hydrogen peroxide and iron shavings concentrations ( $\mathrm{pH} 3$ ). (b) Effect of hydrogen peroxide load over the effluents biodegradability measured as $\mathrm{BOD}_{5} / \mathrm{COD}$ ratio $(50 \mathrm{~g} / \mathrm{L}, \mathrm{pH} 3$ and $90 \mathrm{~min})$. (c) Comparison between COD removal after Fenton's process at the absence and presence of radical scavengers $\left(\left[\mathrm{H}_{2} \mathrm{O}_{2}\right]=32 \mathrm{mM}, 50 \mathrm{~g} / \mathrm{L}, \mathrm{pH} 3\right.$ and $90 \mathrm{~min}$ of reaction).

of hydrogen peroxide over the catalyst followed by the surface reaction between the adsorbed radicals and pollutants, on another hand, others do not discard the possibility of the formation of $\mathrm{HO} \ddot{\mathrm{y}}$ in the bulk due to the interaction of $\mathrm{H}_{2} \mathrm{O}_{2}$ with dissolved iron ions, which will oxidize the organic compounds in the liquid.[30]

In the first approach, the amount of carbon adsorbed in the iron shavings collected after the treatment was evaluated to determine if the COD abatement is truly due to oxidation or by adsorption over the solid surface. A negligible quantity of carbon (below the detection limit of the apparatus) was observed revealing that COD is really eliminated by chemical reaction. Afterwards, the heterogeneity of this system was assessed. For this, the COD removal after $90 \mathrm{~min}$ of Fenton's reaction $(50 \mathrm{~g} / \mathrm{L}$ of catalyst, $\left[\mathrm{H}_{2} \mathrm{O}_{2}\right]=32 \mathrm{mM}$ and $\mathrm{pH} 3$ ) in the absence and presence of two radical scavengers (tert-butanol and potassium iodide) was compared. While the first compound traps both free and surface-bounded hydroxyl radicals, the second is only able to inhibit those adsorbed in the catalyst.[30] The results attained are shown in Figure 2(c). It is clear that the surfactants degradation is due to hydroxyl radicals, since in the presence of tert-butanol, the treatment is completely repressed with negligible COD abatement after 90 min when compared with up to $66 \%$ when no scavenger compound is added. When analysing the effect of KI, one can observe that $<16 \%$ of COD was removed in $90 \mathrm{~min}$. It seems, thus, that the reaction mainly occurs at the catalyst surface with the hydroxyl radicals bounded in the iron shavings; nevertheless, the occurrence of oxidation in the liquid bulk may not be neglected.

\subsection{Nanofiltration}

\subsubsection{Membrane characterization}

Nanofiltration was optimized for the depuration of the surfactant mixture (50:50 in DDB and SLES), being evaluated the effect of pressure drop, $\mathrm{pH}$, temperature and flux of permeated effluent.

The commercial membrane applied for nanofiltration was a DK Osmonics consisting of a thin polyamide composite film with a molecular cut-off range of $150-300 \mathrm{Da}$ and an active filtration area of $140 \mathrm{~cm}^{2}$. While for low $\mathrm{pH}$ values, its surface is positively charged, for alkaline conditions it is negatively charged presenting an isoelectric point at $\mathrm{pH}$ 3.9.[31]

To determine the hydrodynamic resistance (membrane permeability), pure water was used and the permeate flux $\left(J_{\mathrm{v}}\right)$ was evaluated for different pressure drop values $(\Delta P)$. A linear behaviour was found for these two variables and the following relation was attained by linear regression (Equation 1):

$$
J_{\mathrm{v}}=1 \times 10^{-6} \Delta P
$$

The hydrodynamic resistance of the membrane $\left(R_{\mathrm{m}}\right)$ determined by the Darcy equation was $2.5 \times 10^{15} \mathrm{~m}^{2} \mathrm{~m}^{-3}$. 

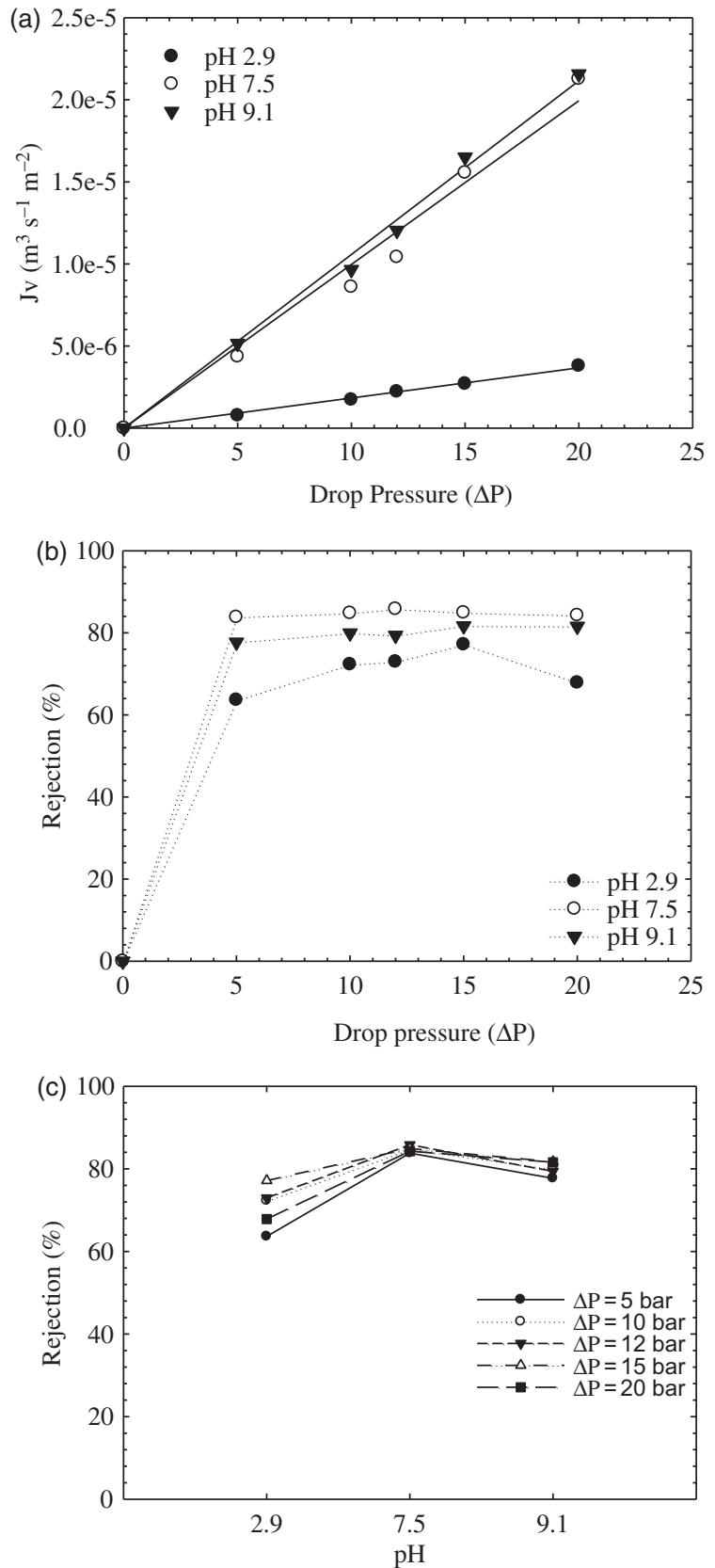

Figure 3. (a) Permeate flux against pressure drop for several $\mathrm{pH}$ values; (b) rejection regarding COD for different $\mathrm{pH}$ values as a function of pressure drop and (c) rejection achieved for different pressure drops as a function of the solution $\mathrm{pH}$.

\subsubsection{Effect of $p H$}

The $\mathrm{pH}$ of the solution is an important parameter affecting the electrostatic interaction between membrane and organic compounds. Thus, the behaviour of the nanofiltration system at different $\mathrm{pH}$ values was analysed in the range $3-9$.

As it can be observed in Figure 3(a), the permeate flux reveals a linear behaviour against pressure drop whichever $\mathrm{pH}$ is used. Moreover, when $\mathrm{pH}$ increases from 2.9 to
7.5 a strong improvement is observed in what regards $J_{\mathrm{v}}$, which also slightly augments for $\mathrm{pH} 9.1$. The relative fluxes, defined as the ratio between the flux of solute (surfactant) and flux of water, were close to $100 \%$ at $\mathrm{pH} 7$ and 9.1, suggesting that under these conditions it is possible to conclude a lower fouling tendency of the membrane. However, a reduction in $18.3 \%$ in the relative flux was found for the filtration at $\mathrm{pH}$ 2.9. In this case, it is likely that the adsorption of the surfactant in the pores occurs due to the electrostatic interactions of the solute with the membrane surface hence anticipating more membrane fouling at low $\mathrm{pH}$ values. High rejection levels were attained for all the range of $\mathrm{pH}$ studied (Figure 3(b)). Even so, the lowest values $(\sim 70 \%)$ were observed for $\mathrm{pH} 2.9$, whereas for 7.5 an increase to around $84 \%$ was detected followed by a small decrease to $80 \%$ at pH 9.

The key parameter for these results is the isoelectric point of the membrane (3.9). At $\mathrm{pH}$ values lower than the isoelectric point, electrostatic attraction between the anionic surfactants and the positively charged membrane occurs. On the other hand, for high $\mathrm{pH}$, both membrane and organic compounds are negatively charged and repulsion is dominant.[19] Figure 3(c) shows that $\mathrm{pH} 7.5$ is clearly the optimum regarding rejection whichever the pressure drop; besides, the performance profile of this membrane initially increases with $\mathrm{pH}$ reaching a maximum value and then decreases for extremely alkaline conditions.

To determine a characteristic parameter $(B)$ of the solute/membrane under study, at different $\mathrm{pH}$ levels, an equation for describing the flux of the solute through the NF membrane was considered as follows:

$$
J_{\mathrm{s}}=B\left(C_{\mathrm{m}}-C_{\mathrm{p}}\right)
$$

where $J_{\mathrm{s}}$ is the diffusive flux of the solute, $C_{\mathrm{m}}$ the solute concentration on the membrane surface and $C_{\mathrm{p}}$ the solute concentration in the permeate. The permeate flux, $J_{\mathrm{v}}$, can be calculated using the following equation:

$$
J_{\mathrm{s}}=J_{\mathrm{v}} C_{\mathrm{p}} \text {. }
$$

Combining Equations (2) and (3) and using the definition of intrinsic rejection, we obtain the following equation:

$$
R_{\mathrm{i}}=\frac{J_{\mathrm{v}}}{J_{\mathrm{v}}+B}
$$

Using the film theory, the relationship between the apparent $\left(R_{\text {app }}\right)$ and intrinsic rejection $\left(R_{\mathrm{i}}\right)$ is given by the following equation:

$$
R_{\mathrm{i}}=\frac{R_{\mathrm{app}} e^{\alpha}}{1-R_{\mathrm{app}}\left(1-e^{\alpha}\right)}
$$

where $\alpha=J_{\mathrm{v}} / k$, being $k$ the mass transfer coefficient for which was assumed the value of $1.24 \times 10^{5} \mathrm{~m} / \mathrm{s}$ estimated by Gomes et al.[21] The Excel platform was used 

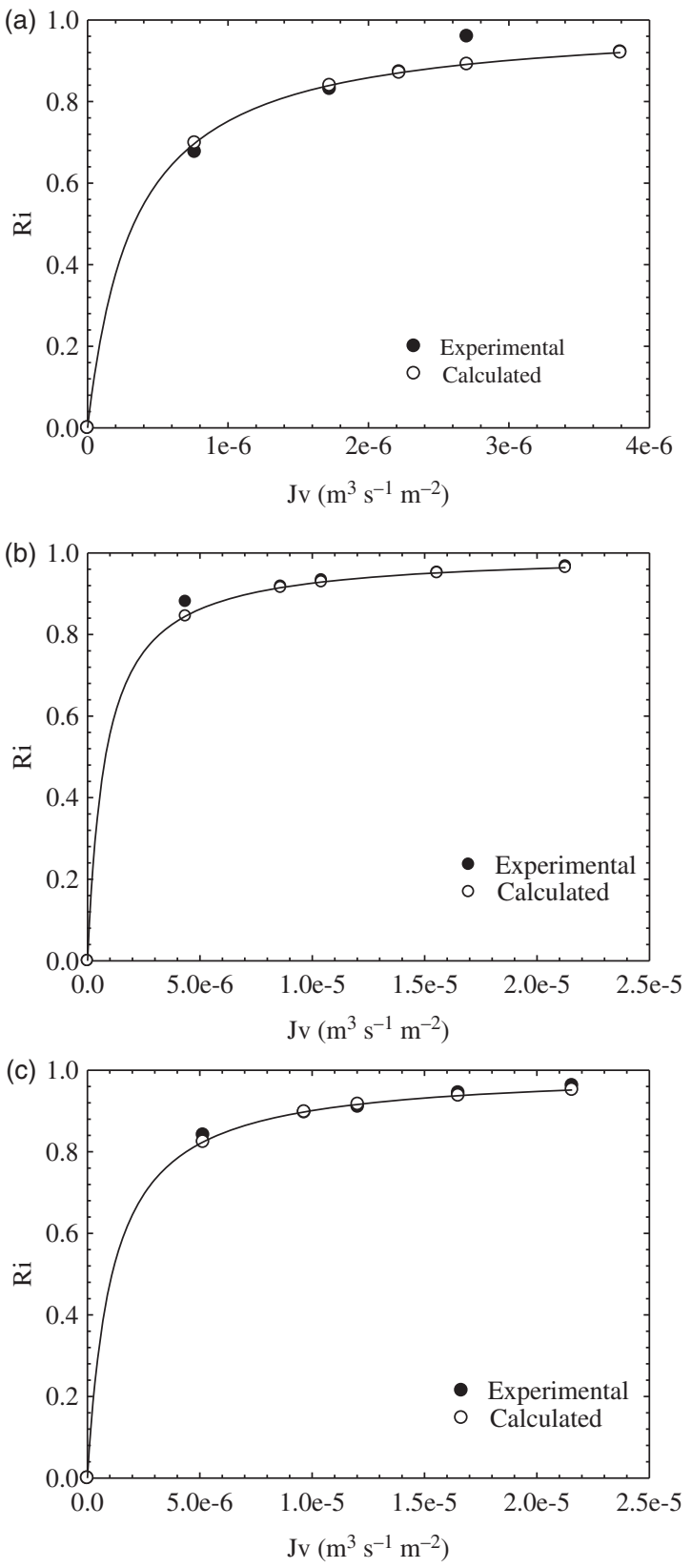

Figure 4. Experimental and modelled intrinsic rejection values as a function of the permeate flux for $\mathrm{pH}$ (a) 2.9, (b) 7.5 and (c) 9.1 .

to obtain the B that minimizes the sum of the squares of the deviations between the calculated (Equation (4)) and the experimental (Equation (5)) $R_{i}$ values. Figure 4(a)-(c) shows a good agreement between the calculated and experimental intrinsic rejection values for the three $\mathrm{pH}$ values under study.

The B values estimated for $\mathrm{pH} 2.9,7.5$ and 9.1 were $3.3 \times 10^{-7}, 9 \times 10^{-7}$ and $11.0 \times 10^{-7} \mathrm{~m} \mathrm{~s}^{-1}$, respectively. Therefore, there is an increase in the B parameter with the $\mathrm{pH}$. Like it was previously discussed, the affinity between the membrane and the solute depends on the magnitude of
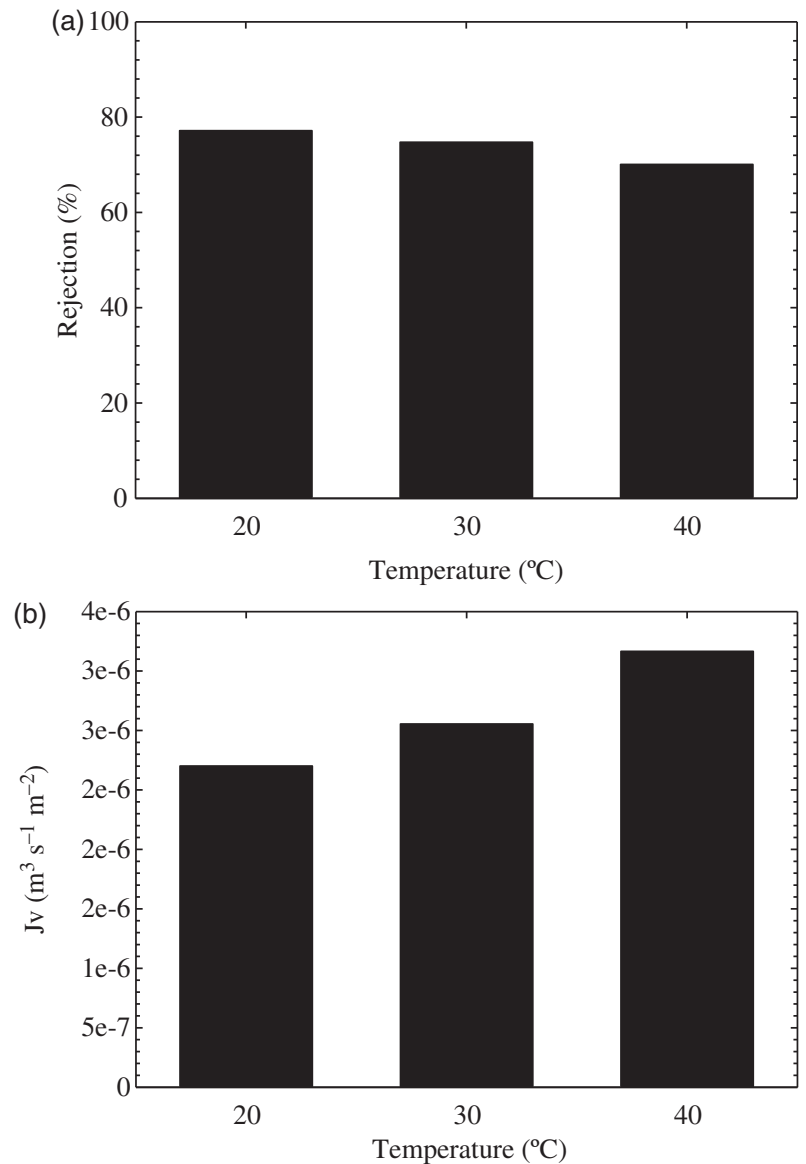

Figure 5. Effect of temperature over (a) COD rejection and (b) permeate flux.

their charges, which are directly associated with the $\mathrm{pH}$ of the solution.

\subsubsection{Effect of temperature}

Temperature is another key variable influencing the NF membrane performance. To evaluate its effect, nanofiltration experiments were conducted at 20,30 and $40^{\circ} \mathrm{C}$ keeping constant the following parameters: $P=15$ bar, $\mathrm{pH}$ 2.9 (original $\mathrm{pH}$ of the simulated effluent) and cross-flow rate $=14.36 \mathrm{~cm}^{3} \mathrm{~s}^{-1}$.

Figure 5(a) shows that the temperature increase causes a decrease in rejection once the diffusion coefficients of the solutes rise with temperature, so that surfactants can pass through the membrane more easily resulting in lower rejection values. Besides, the permeate flow rate increased with temperature (Figure 5(b)), which can be explained by the expansion of the membrane.[19]

\subsubsection{Effect of cross-flow rate}

The tangential flow rate velocity also influences NF performance. To evaluate this effect, the effluent at $\mathrm{pH} 2.9$ was filtrated at two different cross-flow rates (14.4 and 
$11.4 \mathrm{~cm}^{3} \mathrm{~s}^{-1}$ ) using a pressure drop of 15 bar and temperature of $25^{\circ} \mathrm{C}$.

It was observed that with the increasing flow rate the permeate flow rate decreases while the rejection coefficient increases. Unfortunately, due to technical problems, it was not possible to operate with a wider range of cross-flow rates.

Gathering up all the former results, the following operating conditions seem to be optimal for the nanofiltration of the synthetic effluent: $\mathrm{pH} 7.5$; cross-flow rate $14.4 \mathrm{~cm}^{3} \mathrm{~s}^{-1}$, temperature $20^{\circ} \mathrm{C}$ and pressure drop $15 \mathrm{bar}$, leading to a rejection of $84 \%$ correspondent to about $360 \mathrm{mg} \mathrm{O}_{2} \mathrm{~L}^{-1}$ of COD, which is still above the legal limit for wastewater discharge throughout the natural water courses.

\subsection{Processes integration: nanofiltration followed by Fenton's process}

Trying to improve the treatment of this simulated effluent, the permeate obtained from nanofiltration at the optimal conditions referred before was subjected to Fenton's peroxidation over iron shavings $\left(50 \mathrm{~g} / \mathrm{L}\right.$ of catalyst, $\left[\mathrm{H}_{2} \mathrm{O}_{2}\right]=$ $32 \mathrm{mM}$ and $\mathrm{pH} \mathrm{3}$ ). Nevertheless, it was verified that the integration did not bring significant advantage for the wastewater treatment once barely $85 \%$ of COD removal was reached at the end of the depuration, with about $84 \%$ being obtained by nanofiltration.

The biodegradability of the resulting mixture was still analysed to infer about the applicability of a subsequent aerobic system. A low $\mathrm{BOD}_{5} / \mathrm{COD}$ ratio of about 0.1 was detected, which may be attributed to the high amount of iron leached at the end of the Fenton's process $\left(193 \mathrm{mg} \mathrm{Fe} \mathrm{L}^{-}\right.$, the concentration of iron detected in the samples coming from Fenton's process), which may have a negative impact over biomass.

Even if the integration of Fenton's with nanofiltration did not significantly improve the effluents treatment, the individual processes lead to a significant removal of the tested surfactants. In fact, the optimization of Fenton's and nanofiltration allowed abating $66 \%$ and $84 \%$ of COD of the analysed surfactants. These data are important not only for the treatment of detergent industry wastewater but also to improve domestic effluents depuration once the daily use of surfactants that will end up in the municipal wastewaters treatment plants may jeopardize their efficiency and eventually reach the natural water courses.

\section{Conclusions}

The aim of the present research was to study the application of Fenton's process catalysed by iron processing industries wastes (iron shavings) and nanofiltration for the removal of surfactants from a simulated wastewater composed by DDB and SLES.

In what regards the Fenton's process, it was concluded that waste management can be successfully integrated with effluents treatment once the iron shavings were able to promote hydrogen peroxide action over pollutants. It was verified that the system was more efficient under acidic conditions. Moreover, the increase in $\mathrm{H}_{2} \mathrm{O}_{2}$ and catalyst concentration improved COD abatement until a certain point above which the excess on reactants acted as radical scavengers. In this context, the best COD (66\%) removal was attained for $\left[\mathrm{H}_{2} \mathrm{O}_{2}\right]=32 \mathrm{mM}$ and $50 \mathrm{~g} / \mathrm{L}$ of iron shavings. The effect of the presence of two radical scavengers (KI and tert-butanol) permitted to settle that oxidation mainly occurred through hydroxyl radicals bounded to iron metal, but the production of these moieties in the bulk due to the reaction between hydrogen peroxide and dissolved iron may not be neglected.

Nanofiltration showed high potential on COD removal. The effect of the key operating conditions was analysed, and it was concluded that COD abatement was higher for $\mathrm{pH}$ values near neutrality ( $\mathrm{pH} 7.5)$. On the other hand, the increase in temperature reduced efficiency and the same behaviour was found when the effect of cross-flow rate was analysed. In this regard, $84 \%$ of COD rejection was attained for $\mathrm{pH} 7.5$, cross-flow $14.3 \mathrm{~cm}^{3} \mathrm{~s}^{-1}, 20^{\circ} \mathrm{C}$ and $15 \mathrm{bar}$ of pressure drop.

The integration scheme involving nanofiltration followed by Fenton's over iron shavings under the optimal conditions was analysed; however, no significant improvement was observed. Even so, both treatment systems seem individually to have potential on the abatement of surfactants from wastewater.

\section{Funding}

Rui C. Martins gratefully acknowledges the Fundação para a Ciência e Tecnologia, Portugal, for the financial support under the Pos-Doc grant [BPD/72200/2010].

\section{References}

[1] Silva S, Chiavone-Filho O, Neto E, Mota A, Foletto E, Nascimento C. Photodegradation of non-ionic surfactant with different ethoxy groups in aqueous effluents by the photoFenton processes. Environ Technol. 2014;35:1556-1564.

[2] Kaleta J, Elektorowicz M. The removal of anionic surfactants from water in coagulation process. Environ Technol. 2013;34:999-1005.

[3] Bautista P, Mohedano A, Gilarranz M, Casas J, Rodriguez J. Application of Fenton oxidation to cosmetic wastewater treatment. J Hazard Mater. 2007;143:128-134.

[4] Neyens E, Baeyens J. A review of classic Fenton's peroxidation as an advanced oxidation technique. J Hazard Mater. 2003;98:33-50.

[5] Rodrigues C, Boaventura R, Madeira L. Technical and economic feasibility of polyester dyeing wastewater treatment by coagulation/flocculation and Fenton's oxidation. Environ Technol. 2014;35:1307-1319.

[6] Martins RC, Amaral-Silva N, Quinta-Ferreira RM. Ceria based solid catalysts for Fenton's depuration of phenolic wastewaters, biodegradability enhancement and toxicity removal. Appl Catal B. 2010;99:135-144. 
[7] Rossi A, Amaral-Silva N, Martins RC, Quinta-Ferreira RM. Heterogeneous Fenton using ceria based catalysts: effects of the calcination temperature in the process efficiency. Appl Catal B. 2012;111:254-263.

[8] Jiang C, Xu Z, Guo Q, Zhuo Q. Degradation of bisphenol A in water by the heterogeneous photo-Fenton. Environ Technol. 2014;35:966-972.

[9] Martins RC, Lopes DV, Quina MJ, Quinta-Ferreira RM. Treatment improvement of urban landfill leachates by Fenton-like process using ZVI. Chem Eng J. 2012;192: 219-225.

[10] Zhou H, Smith D. Advanced technologies in water and wastewater treatment. J Environ Eng Sci. 2002;1: 247-264.

[11] Mensah K, Foster C. An examination of the effects of detergents on anaerobic digestion. Bioresour Technol. 2003;90:133-138.

[12] Kowalska I, Majeswaska-Nowak K, Kabsch-Korbutowicz $\mathrm{M}$. Influence of temperature on anionic surface active agent removal from a water solution by ultrafiltration. Desalination. 2006;162:33-40.

[13] Lin S, Lin C, Leu H. Operating characteristics and kinetic studies of surfactant wastewater treatments by Fenton oxidation. Water Res. 1998;33:1735-1741.

[14] Perkowski P, Józwiak W, Kos L, Stajszczyk P. Application of Fenton's reagent in detergent separation in highly concentrated water solutions. Fibres Text East Eur. 2006;14: 114-119.

[15] Pagano M, Lopez A, Mscolo G, Cionarella R. Oxidation of nonionic surfactants by Fenton and $\mathrm{H}_{2} \mathrm{O}_{2} / \mathrm{UV}$ processes. Environ Technol. 2008;29:423-433.

[16] Martins RC, Silva A, Castro-Silva S, Garção-Nunes P, Quinta-Ferreira R. Advanced oxidation processes for treatment of effluents from detergent industry. Environ Technol. 2011;32:1031-1041.

[17] Naumczyk J, Bogacki J, Marcinowski P, Kowalik P. Wastewater treatment by coagulation and advanced oxidation processes. Environ Technol. 2014;35:541-548.

[18] Wang X, Song Y, Mai J. Combined Fenton oxidation and aerobic biological processes for treating a surfactant wastewater containing abundant sulfate. J Hazard Mater. 2008; 160:344-348.

[19] Kaya Y, Barlas H, Arayici S. Nanofiltration of cleaning-inplace (CIP) wastewater in a detergent plant: effects of $\mathrm{pH}$, temperature and transmembrane pressure on flux behaviour. Sep Purif Technol. 2009;65:117-129.

[20] Kertész S, Lászlób Z, Horváthb Z, Hodúrb C. Analysis of nanofiltration parameters of removal of an anionic detergent. Desalination. 2008;221:303-311.

[21] Gomes S, Cavaco SA, Quina MJ, Gando-Ferreira LM. Nanofiltration process for separating $\mathrm{Cr}$ (III) from acid solutions: experimental and modelling analysis. Desalination. 2010;254:80-89.

[22] Greenberg A, Clesceri L, Eaton A. Standard methods for the examination of water and wastewater. Washington, DC: American Public Health Association; 1985.

[23] Esplugas S, Contreras S, Ollis D. Engineering aspects of the integration of chemical and biological oxidation: simple mechanistic models for the oxidation treatment. J Environ Eng. 2004;130:967-974.

[24] Archer A, Mendes A, Boaventura R. Separation of anionic surfactant by nanofiltration. Environ Sci Technol. 1999;33:2758-2764.

[25] Eckenfelder W. Industrial water pollution control. 3rd ed. Singapore: McGraw-Hill; 2000.

[26] Pignatello J. Dark and photoassisted $\mathrm{Fe}^{3+}$-catalyzed degradation of chlorophenoxy by hydrogen peroxide. Environ Sci Technol. 1992;26:944-951.

[27] Martins RC, Rossi AF, Quinta-Ferreira RM. Fenton's oxidation process for phenolic wastewater remediation and biodegradability enhancement. J Hazard Mater. 2010;180:716-721.

[28] Kallel M, Belaid C, Mechichi T, Ksibi M, Elleuch B. Removal of organic load of phenolic compounds from olive mill wastewaters by Fenton oxidation with zero-valent iron. Chem Eng J. 2009;150:391-395.

[29] Ramirez J, Costa C, Madeira L, Mata G, Vicente M, RojasCervantes M, López-Peinado A, Martín-Arada R. FentonLike oxidation of Orange II solutions using heterogeneous catalysts based on sepionite clay. Appl Catal B. 2007;71: 44-56.

[30] Xu L, Wang J. A heterogeneous Fenton-like system with nanoparticles zero-valent iron for removal of 4-chloro-3methyl phenol. J Hazard Mater. 2011;186:256-264.

[31] Al-Amoudi A, Williams P, Mandale S, Lovitt R. Cleaning results of new and fouled nanofiltration membrane characterized by zeta potential and permeability. Sep Purif Technol. 2007;54:234-240. 